DOI: http://dx.doi.org/10.12660/gvcasosv8n1c4

\title{
EINAR OU LILI? OS DESAFIOS DE UMA TRANSEXUAL NO MERCADO FORMAL DE TRABALHO
}

Einar or Lili? A transgender woman's challenges in the formal job market

Maurício Donavan Rodrigues Paniza - mauriciopaniza@ gmail.com

Escola de Administração de Empresas de São Paulo da Fundação Getulio Vargas - São Paulo, SP, Brasil

ELISA YoSHIE ICHIKAWA - eyichikawa@uem.br

Universidade Estadual de Maringá - Maringá, PR, Brasil

Marcio Pascoal CASSANDRE - mcassandre@ hotmail.com

Universidade Estadual de Maringá - Maringá, PR, Brasil

Submissão: 09/12/2017 | Aprovação: 21/02/2018

\begin{abstract}
Resumo
O caso de ensino relata a trajetória de uma trabalhadora transexual e suas tentativas para se inserir e permanecer no mercado formal de trabalho. A situação retratada, apoiada em fatos reais, permite debates e problematizações relacionadas ao campo de Gestão de Pessoas, no que se refere à gestão da diversidade e da diferença nas empresas. Embora Lili tenha conseguido se inserir no mercado formal de trabalho, ela passou por diversas situações que ilustram possibilidades para examinar as políticas internas de Gestão de Pessoas.
\end{abstract}

Palavras-chave: transexualidade, identidade de gênero, inclusão, gestão da diversidade, gestão de pessoas.

\section{Abstract}

The teaching case reports the trajectory of a transsexual worker and her attempts to enter and remain in the formal job market. The situation portrayed, supported by real facts, allows debates and problematizations related to the People Management field, regarding the management of diversity and difference in organizations. Although Lili was able to enter the formal job market, she went through a number of situations that illustrate possibilities for discussing People Management policies.

Keywords: transsexuality, gender identity, inclusion, diversity management, people management.

\section{Introdução}

Este caso de ensino, escrito a partir de fatos reais, analisa a trajetória de Lili. Nascida Einar, Lili é uma mulher transexual que, ao contrário das previsões para pessoas com a sua identidade de gênero, conseguiu ingressar no mercado formal de trabalho e concluir um curso técnico. Lili é uma exceção à regra, porque a maioria das travestis e transexuais no Brasil tem na prostituição a única forma de acessarem o trabalho. Falar da trajetória da trabalhadora Lili é falar de um tema pouco conhecido nas áreas de Administração e de Gestão de Pessoas. Nesse sentido, conhecer a história e as experiências profissionais da Lili pode subsidiar debates pertinentes relacionados à gestão de pessoas e da diversidade de gênero nas organizações. 
A escolha pelos nomes Einar e Lili foi inspirada em Lili Elbe. Nascida Einar Wegener, Lili é conhecida como a primeira mulher transgênero a ter se submetido a uma cirurgia de redesignação sexual. Sua vida inspirou o romance ficcional A garota dinamarquesa, de David Ebershoff, publicado na década de 2000, e adaptado para um filme homônimo, lançado em 2015.

\section{Quando Lili era Einar...}

Lili tem 21 anos e nasceu Einar, em um município do interior com aproximadamente 12 mil habitantes. Desde a infância, ela se sentia diferente dos demais meninos. Ela recorda que costumava brincar experimentando as roupas e sapatos da mãe, e que, quando criança, aparentava ser um menino com trejeitos afeminados. Aos oito anos, Lili tinha os cabelos loiros cacheados compridos. Em certa ocasião, um amigo do pai perguntou-lhe sobre a filha. Mas a filha era filho. A ocasião incomodou o pai de Lili de tal forma que ele lhe raspou os cabelos compridos, para que ninguém mais pensasse que seu filho era mulher.

Quando adolescente, ainda Einar, Lili exprimiu o desejo de um dia estudar Enfermagem, do que o pai discordou: "Isso é coisa de gay! Você tem que ser um médico, um advogado...". Por volta dos 15 anos, Lili conseguiu seu primeiro emprego, como auxiliar em um salão de beleza em sua cidade natal. No entanto, ela não desejava trabalhar por muito tempo naquele setor, embora soubesse que era uma das áreas mais abertas a receber trabalhadores afeminados. "Eu não tenho amigas que trabalham a não ser como maquiadoras, cabeleireiras, tem algumas até que são estilistas. Mas a maioria são garotas de programa, são profissionais do sexo", pondera Lili sobre a relação entre trabalho e transexualidade. Poucos meses depois, soube de um emprego de balconista em uma panificadora de uma cidade metrópole de quase 600 mil habitantes, vizinha à sua cidade natal. Como Einar, Lili foi admitida no estabelecimento. E foi nesse momento que ela iniciou a transição para o gênero feminino, aos 17 anos, certa de que era uma mulher nascida em um corpo masculino.

\section{Quando Einar quis ser Lili...}

Quando chegou à adolescência, por volta dos 16 anos, Lili estava certa de que não queria ser homem. Chamou a mãe para uma conversa: "Quero ter seios!". A conversa deixou a mãe preocupada, mas, ainda assim, ela apoiou o desejo da filha. Os clientes da panificadora acompanharam a transformação do corpo do balconista: "Lá, eu entrei de uma forma, como Einar, e saí como Lili". A trabalhadora só conseguiu realizar a intervenção cirúrgica para o implante de próteses de silicone nos seios porque tinha o emprego na panificadora, e assim foi economizando seu salário para que pudesse investir no seu corpo feminino.

Quando decidiu iniciar a transição de gênero, Lili contou com o auxílio profissional de um médico, que a orientou no processo de ingestão de hormônios para que o corpo se adaptasse aos seios. Quando acordou da cirurgia, Lili se recorda, emocionada: "Eu tenho peito agora, sou uma pessoa diferente. O sonho de uma transgênero é ter seios, porque os seios são a feminilidade da mulher". A trabalhadora ainda se recorda de que também se sentiu grata, não apenas pelos seios, mas por, na ocasião, estar trabalhando: "Não era o melhor trabalho do mundo, mas eu trabalhava. Tive muitas amigas que não tiveram a mesma sorte, tiveram que se prostituir, talvez até por pouco dinheiro, questão assim de reais mesmo. Mas mais porque não têm as oportunidades de vida, as portas não se abrem, as pessoas te julgam, as pessoas te condenam, é difícil”, concluiu.

\section{Educação}

Lili cursou do ensino básico até o ensino médio em escolas públicas de sua cidade natal, segundo ela, bem-recebida pelos professores e trabalhadores da escola. Era bem-tratada pelos colegas e professores. No entanto, na época da adolescência, como estava vivendo o início da transição de gênero, ficava constrangida de usar os banheiros, tanto masculino quanto feminino, da escola. A partir disso, ela acabava deixando de fazer as necessidades fisiológicas no ambiente da 
escola porque não queria constranger os colegas, afinal, ela era homem ou mulher? Ao saber do ocorrido, os professores de Lili decidiram oferecer o seu banheiro exclusivo para que ela pudesse usá-lo.

Ao concluir o ensino médio, Lili decidiu procurar um curso técnico de Enfermagem. Assim como os outros candidatos, ela foi submetida a um processo seletivo e uma entrevista com uma psicóloga, em que foi aprovada. Porém, no início das aulas, Lili foi surpreendida com a imposição de que, caso quisesse permanecer aluna do curso, deveria cortar seus cabelos, porque ouviu de uma representante do curso que "homem era homem e mulher era mulher". Lili até estava disposta a vestir-se de homem, caso fosse imprescindível para cursar Enfermagem, no entanto recusou-se a perder os cabelos, como já havia acontecido na infância. Desistiu desse curso e procurou outro.

No segundo curso em que se matriculou, Lili foi bem-recebida pelo corpo docente, e, dessa vez, sua identidade feminina não foi barreira para que ela permanecesse no curso. Nessa nova experiência, o único estranhamento dos professores era ter que chamar o nome masculino de Lili, o que eles consideravam constrangedor. Assim, em acordo com todos os professores, embora o registro formal trouxesse o nome Einar, o tratamento dado durante o curso foi de Lili, no feminino. Lili concluiu o curso técnico de Enfermagem em dezembro de 2015 e, alguns meses depois, conseguiu um emprego na área.

\section{Imagem negativa}

Sobre a imagem predominante que a sociedade tem de uma transexual, Lili é enfática ao dizer que é a de uma pessoa com linguagem chula, vulgar, e que transita pelas ruas nua. "Quando você é trans, as pessoas te acham uma pessoa 'fácil'. E que, por isso, você tem que estar sempre aberta a aceitar toda e qualquer proposta de cunho sexual. Com os homens, realmente é assim. As mulheres acolhem mais", analisa Lili.

Por exemplo, há um cliente na panificadora que se recusa a ser atendido por Lili. A trabalhadora nunca o maltratou, mas, há algum tempo, ele foi direto e objetivo com ela: "Prefiro que você não me atenda". Quando esse cliente chega, Lili já direciona alguma outra colega de equipe para atendê-lo. Muitas pessoas, principalmente homens, perguntam diretamente a Lili se ela "faz programa". Algumas até se desculpam e justificam a pergunta: "Poxa, me desculpe. É que a maioria faz, então eu achei que você fizesse". Esse tipo de situação entristece Lili.

\section{Uma transexual na empresa? Ações e reações}

Quando trabalhara no salão, Lili ainda era Einar. Quando começou a trabalhar como balconista de padaria, também ainda era Einar. A trabalhadora estava bastante temerosa da recepção da sua patroa e da clientela do estabelecimento em relação à sua transição de gênero. "Meus patrões foram me acompanhando gradualmente, viram que eu estava mudando cada vez mais. Quando eu falei para eles que eu ia pôr prótese de silicone, minha patroa ficou assim, bem chocada: 'Nossa, você realmente vai querer por?! Mas faz, se essa é a sua vontade, você vai ser muito bem recebida"'. Assim, Lili ficou mais tranquila, porque seu "emprego estaria salvo [...] Eu sempre deixei bem claro que seria apenas um volume a mais. Mas o meu comportamento, educação, iriam continuar os mesmos", relata a trabalhadora.

Quando retornou à panificadora como mulher, Lili expôs um início difícil: as pessoas olhavam com estranhamento: “Um menino que agora é menina, como assim?". Com o tempo, os clientes habituais acostumaram-se à partida de Einar e à chegada de Lili. Como balconista, Lili recebeu conselhos de pessoas próximas, inclusive de sua patroa, de que continuasse a estudar, de que lutasse para manter seu lugar no mercado formal de trabalho. Foi nessa perspectiva que, enquanto era balconista, Lili iniciou e concluiu seu curso técnico em Enfermagem.

Apesar da aceitação da patroa sobre o fato de a trabalhadora ter assumido sua identidade de gênero feminina, ela observava que Lili era abordada pelos clientes homens de uma forma diferente 
daquela que eles destinavam às trabalhadoras cisgênero. Com isso, a empresária sempre orientava Lili a não usar maquiagens que fossem muito chamativas nem manter as unhas compridas. Lili demonstrava consciência sobre a necessidade de estar "adequada" ao ambiente, mas recorda-se de que o tratamento relativo à aparência acabava não sendo o mesmo para as trabalhadoras cisgênero, que se maquiavam sem sofrer esse tipo de intervenção da patroa. A empresária justificava essa postura com Lili como necessária para protegê-la do assédio dos homens. Lili questionava: "Por que eu não posso, e elas sim?". Ao que a patroa respondia: “Lili, eu não sei. Eu não quero que as pessoas tenham uma má impressão, que você esteja com um batom escuro, forte, no seu local de trabalho. Eu quero você uma pessoa assim, mais delicada, mais meiga, e eu quero que você passe essa impressão para os clientes".

Por falar em assédio, a própria Lili reconhece que a abordagem masculina muitas vezes vem acompanhada pelo viés de percepção de que, se uma pessoa é transexual ou travesti, ela automaticamente é uma prostituta. São comuns, no dia a dia de trabalho de balconista, homens que lhe pedem o telefone, que a convidam para sair ou mesmo que já chegaram até ao ponto de seguir a trabalhadora, importunando-a na rua após o expediente. Não que Lili considerasse que as colegas de trabalho cisgênero não eram assediadas. Pelo contrário, também o eram. Mas tanto Lili como sua patroa percebiam que a abordagem à mulher transexual era mais direta e incisiva, enquanto com as mulheres cisgênero era uma coisa mais sutil, denotando o estereótipo predominante de que, ainda que tenha um trabalho formal, a transexual se prostitui em outros horários. A diferença de tratamento incomodava a patroa de Lili, que questionava: "Os homens mexem muito com você, os homens pedem telefone para você, e é impressionante porque eles não fazem isso com as meninas que trabalham na panificadora".

Um cliente da panificadora, médico, foi uma das pessoas que aconselhavam Lili em sua trajetória profissional. Ele sabia que ela estava se preparando para ser técnica em Enfermagem e sempre lhe perguntava: "Já se formou? Avisa quando terminar o curso, que eu vou te indicar para o hospital". Até que o dia chegou. Lili fez o processo seletivo e foi aprovada para trabalhar no hospital, uma organização confessional vinculada a uma entidade religiosa. Durante alguns meses, ela continuou nos dois empregos: como balconista na panificadora de manhã, e técnica de Enfermagem no hospital à tarde.

Quando Lili ingressou no quadro de trabalhadores do hospital, foi chamada no setor de Recursos Humanos, onde recebeu algumas orientações: "Lili, como vai ser? Você precisa usar o banheiro feminino, trocar-se no banheiro feminino, não tem como você ir para o banheiro masculino". Ao que Lili respondeu: "Eu até prefiro...". De qualquer forma, Lili disse que até não se incomodaria caso não tivesse lugar onde se trocar, ela disse que poderia se trocar em casa porque realmente precisava daquele emprego. No setor onde Lili trabalharia, apenas os chefes, as enfermeiras-chefes, os médicos e as coordenadoras sabiam que "entraria" uma transexual no setor do Centro Cirúrgico.

No primeiro dia de trabalho, Lili percebeu muitos olhares, e acredita que seus futuros colegas de trabalho já sabiam de sua contratação. Eles foram cumprimentá-la e disseram: "Seja bem-vinda, você vai ser muito bem recebida aqui’". Quando Lili começou a se ambientar na cultura do hospital, soube que havia uma brincadeira entre as equipes, algo inspirado em um programa televisivo como: “É menino ou menina?". Os colegas preocuparam-se em conversar com Lili para alertar que, caso ocorresse a brincadeira, já era um hábito entre a equipe de trabalho, mas não seria pelo fato de Lili ser transexual.

Quanto ao uniforme no hospital, Lili afirmou que a roupa do centro cirúrgico sempre é a mesma, tanto para homem quanto para mulher. Mas o que deixou a trabalhadora bastante satisfeita é que o crachá funcional foi confeccionado com a identidade de Lili, e não de Einar. O departamento de Recursos Humanos considerou que seria constrangedor a trabalhadora utilizar crachá como Einar, tendo uma identidade feminina. "Eu achei legal, eles foram muito humanos. Lili, técnica de 
EINAR OU LILI? OS DESAFIOS DE UMA TRANSEXUAL NO MERCADO FORMAL DE TRABALHO Maurício Donavan Rodrigues Paniza, Elisa Yoshie Ichikawa, Marcio Pascoal Cassandre

Enfermagem. Nossa, eu fiquei muito feliz! Minhas amigas veem e ficam muito felizes. Meu, você está conquistando seu espaço!". Diante das conquistas, Lili estava certa de que o próximo passo em sua vida era ingressar na faculdade de Enfermagem. Com o trabalho formal no hospital, poderia, então, pensar em viabilizar a continuidade de sua capacitação profissional. 